\title{
Expert's Technical Review on 2D Games with Religious Elements
}

\author{
Norkhairani Abdul Rawi, Maizan Mat Amin, Azilawati Rozaimee and Wan \\ Malini Wan Isa \\ Faculty of Informatic and Computing, Universiti Sultan Zainal Abidin (UniSZA), \\ Kampus Tembila, 22200 Jerteh, Terengganu, Malaysia \\ \{khairani,maizan,azila,wanmalini\}@unisza.edu.my
}

\begin{abstract}
Previously, we present the motivation for developing 2D game named My Vourney to the Mosque (MJTM) that enables to teach children to recite zikir indirectly. There is a need for usability evaluation of the prototype before it can be tested against actual user. Therefore, in order to verify the prototype that has been developed, a usability study was conducted among technical experts. The experts were one from Islanc entertainment industry and two academicians from Multimedia School. A questionnaire has been developed to collect feedback from the expert reviewer. Among the aspects observed by the experts were contents, navigation or interactivity, presentation of the prototype and the use of animations. These are important@aspects to be considered according to various previous studies. Results shown that most of the aspects observed by the reviewers were above the average score of 4.00 according to the Likert scale. Findings of this study will be used as a guideline for further enhancements of the prototype.
\end{abstract}

Keywords: 2 D games, zikir recitation, Istamic games, multimedia application, usability

\section{Introduction}

Including video games, computer games are one of the favorite activities among children in the world. The avarlability and affordability of devices for playing games also a pushing factor towards this situation. Games as we know provide positive and negative effects. Video games have been around for nearly 50 years [1] as noted by Kirschin 2010, the first game is Spacewar that released in 1962. According to the most recent comprehensive poll by the Kaiser Foundation, American children aged 8-18 play an average of eight hours of video games per week, an increase of over 400 per cent from 1999 [2]. Playing is heaviest in the 11-14 age groups, with boys out playing girls more than 2.5 hous to 1 . A recent study reports that around 99 per cent of American boys play video games, along with 94 per cent of girls [3]. It is common in US children and adolescents to play more than 20 hours per week. The numbers keeps on growing with the avaltability and affordability of smart phone devices that enables for the games to be on mobile and always on the go.

Although the types of games vary, in some way, content analyses by [4] show that the major ity of top selling video games and children's favourite games contain violence, and often strong violence. More recently, Call of Duty: Modern Warfare 2 grossed $\sim$ \$SD 550 million in the first five days of its 2009 release, at that time more than any other entertainment product in history (movies included). Next on the list in 2009 was a Grant Theft Auto IV (GTA), with \$USD 500 million in five days. Even more recently (a year is a long time in the video game world) Call of Duty: Black Ops grossed \$USD 360 million in a single day, breaking all records recorded by Ortutay in 2010 and reported in [1]. According to Wikipedia, the massive multiplayer online game (MMOG) World of Warcraft has more than 12 million online subscribers and thus currently grosses more than \$USD 180 million per month (at \$15 per month per player). GTA, which is rated 
M17+ in the United States and involves such activities as going on murderous rampages, having sex with prostitutes and then murdering them to retrieve the money paid, has been played by 56 percent of United States children aged 8-18 [2]. Clearly, a large number of children and adolescents are exposed regularly to video games with high levels of violence and anti-social themes. It is a great responsibility to parents, educators and professionals who work with children to have some knowledge of the games' bad influences and effects.

Report on the game as scripted above lead us provide alternatives games to the children in order to eliminate bad elements on current available games. It is our motivation to bring along the religious elements such as zikir in Islam and the use of multimedia in 2D game for children. A prototype of 2D game named My Journey to The Mosque (MJTM) had been developed by incorporating zikir as tools for defeating the evils [5].

In order to verify the games developed fulfill the technical aspects before it can be tested against actual user for usability and acceptance, an expert review towards the game has been conducted. This process is purposely carried out to determine oop of holes in technical side so further improvement can be made. The details of the technical review will be discussed in this paper.

The organization of this paper is as follows Section I will briefly explained the problem and motivation of this research. Section II will discuss on related works in multimedia as delivery medium and evaluation techniques used in previous research. Methodology of research is deliberated in Section III andSection IV talk over on results and discussion. Lastly, conclusion will be conversed to conclude overall findings on this research.

\section{Related Work}

This section will report on literature review on related areas within this research. The exploitation of multimedia in engaging user will be discussed and its role in information delivery. The main issues that need to review is the evaluation process that normally taken place in order to verify a few aspects of multimedia application. The conclusion of this section will be the main input in the next part of the research where it provides the guide on how and what evaluation should be conducted.

\subsection{Multimedia as Information Delivery Medium}

There are manyapproaches that can be used to deliver information in interesting ways for example by usirg an interactive application, simulations and animations. Nowadays computer games are one of the approaches to convey information effectively.

This approach has been applied in many domains such as biomedical, health science, training, ducation and entertainment. In education domain, games have been recognized as being a good tool to promote learners to actively participate in learning activities [6-8]. Many studies have been conducted on games-based learning and they conclude that it could be the best way to trigger students' learning, motivation [9-12]. Besides that, a study from researchers [13] reported that a game-based learning approach might provide a good chance to stimulate children's abstract thinking during the process of cognitive development, and further foster their higher order thinking ability. As a result, many researchers have developed games for education or learning purpose [14].

A previous study from [15] stated that by using game-based learning approach, learning achievements among student are increased significantly. It shows that computer game based instruction can effectively promote students' nutrition knowledge. Research from [16] reported that teachers and students could adapt well to this kind of approach as a learning tool and they will convey positive sign of interest in utilizing it in the future.

Several previous studies have demonstrated the ease of use and usefulness features of computer games by applying the game-based learning approach to a variety of learning 
activities [17-18]. For example, [19] stated that using computer games for learning in elementary schools can increase the internal motivations and learning achievements of students. [20] Indicated that through computer games which focus on nutritional education in primary and secondary schools, the learning motivations and learning achievements of the students can be increased, and their competences and know ledge can be promoted. [21] also pointed out that through computer games, children's learning interests are effectively promoted, and they are guided to actively improve their food and drink habits.

\subsection{Multimedia Application Evaluation}

Evaluation is a process that critically examines ongoing or completed project or program. It involves collecting and analyzing information about a project's activities, characteristics, and outcomes. Its purpose is to make judgments about a project, to improve its effectiveness, and/or to inform programming decisions [22] In multimedia field, evaluation is carried to serves a few purposes. One of them is the usability level of application [23]. Evaluation is also a tool to get information for improvements on certain criteria of the application.

Several approaches of evaluation have been done by previous researcher such as Evaluation of Multimedia, Pedagogical and Interactive software (EMPI) [24] and usability testing [25]. EMPI were design to assist user in evaluating multimedia learning software by listing several evaluation, criteria. The evaluation criteria are group six approaches which are: 1) general feeling- ineorporate images offered by the software, 2) computer science quality- evaluation of the techntcafrealization, 3) usability- ergonomics of the interface, 4) multimedia documents-Cevaluation of multimedia elements, 5) scenario- wiring techniques to design information, 6) didactical module- integrate pedagogical starter, tutoring and situation. [24] Have founded their method on a questionnaire that allows the marking of each previously quoted criterion.

Meanwhile theoreticat model of ICT evaluation have been set up by [26] for new Lleida Museum environment. This model identifies three categories of people as the respondents which are visitors, cultural operators and technologist that involve in human computer interaction, cybermuseography and interpretation and behavior and meaning. These processes were evaluated separately by setting up interviews, direct observation, questionnaires and video observation. This method can identify different anomalies in the museum's ICT applications, according to different perspective of technology, cultural communications and visitor response.

Research has done by [25] detail out the concept of usability testing which aims at providing a means of identifying problem area, and the extracting of information concerning problems, difficulties, weakness and area for improvement. The dimensions of usabilify testing are learnability, performance effectiveness, flexibility, error tolerance and system integrity and user satisfaction. Data collection method for usability testing includes observation, interview/verbal report, thinking-aloud, questionnaire, video analysis, auto data logging program and software support.

Another research by [27] outlines the evaluation criteria and the approach to evaluate multimedia technologies in three domains: instructional and conceptual design, interface and graphic design and user attitudes and affect. Instruction and conceptual domain comprise of five criteria: 1) introductory objectives and directions, 2) navigations and orientation, 3) interactivity, 4) sequencing and 5) consistency between learning objectives and content of instruction. Evaluation criteria for interface and graphic design are 1) color, 2) frames, 3) text, 4) types of media, 5) animation and 6) graphics. Finally for user attitudes and affect cover issued such as 1) effectiveness, 2) efficiency, 3) usefulness, 4) degree of interest, 5) enjoy ability, 6) appeal, 7) degree of user-friendliness, 8) relevancy and 9) degree of engagement. This evaluation was carried out using two set of questionnaires with the items that corresponded to the criteria in the evaluation domain. 
Based on the literature review conducted, it can be concluded there are few aspects need to be considered against prototype developed to ensure it fulfill the important characteristics. From the previous work, the evaluation criteria has been selected according to the suitability in technical aspects. Contents, navigation/interactivity, application presentation and animation has been chosen as main aspects to be evaluated.

\section{Methodology}

This section will report on the methodology in conducting technical review phase. The questionnaire named Penilaian Teknikal Permainan Komputer (PTPK) has been developed based on the criteria of contents, navigation/interactivity, application presentation and animation. Likert scale of 1 to 5 is used to measure each of the criteria in every aspect. The selection of the criteria based on few previous work reported in [24-27]. Hybrids types of criteria are selected as the evaluation taken part not only focus on usability or technical or interface only.

A pilot study by a board of academicians at School of Multimedia in Universit i Sultan Zainal Abidin (UniSZA) had been done to verify the refiability of items in the instrument. Next, the technical review session is conducted in Multimedia laboratory. The evaluation form has been distributed before the presentation session start to give the guide on each aspect that need to be focused by the experts. The application has been presented to the experts by the developer. During the presentation, each/of the functionality is demonstrated to the reviewer and the reviewer is free lo ask anything during the presentation session. The session took around 30 minutes. Figure 1, Figure 2, Figure 3 and Figure 4 are snapshots of the games that previewed to the reviewer [5].

\subsection{Questionnaires Setup}

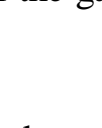

Since the evaluation carcied out purposely to identify strength and weakness of the 2D games, a questionnaire of hybrid critepia in four main aspects have been constructed to be used as instruments. The aspects that will be focused in the evaluation are contents, navigation/interactivity, application presentation and animation.

\subsection{Presentation Setup}

The games are projected to the screen and shown on how it can be played. The games are played by the presenter and all the supporting component's functions have been explained in details. After the presentations end, a question and answer (QA) session is made available to enable the reviewer prompting any question or confusion regarding the game.

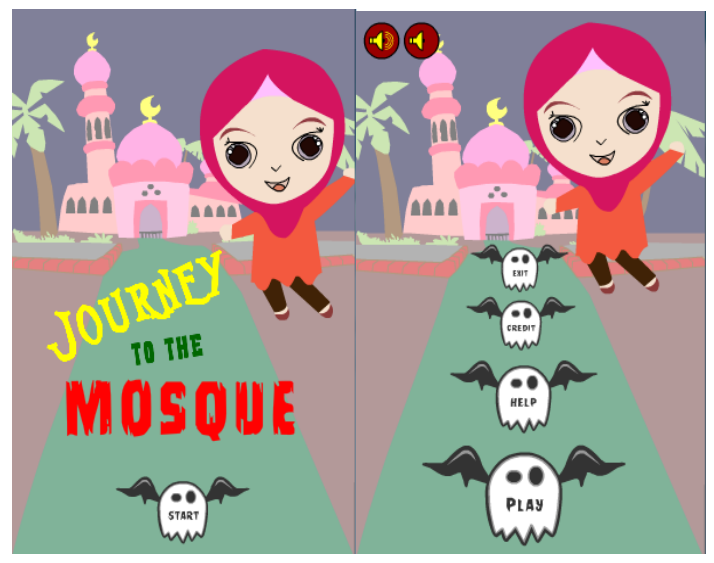

(i)

(ii)

Figure 1. The Start Page (i) and Main Menu (ii) of the Games 


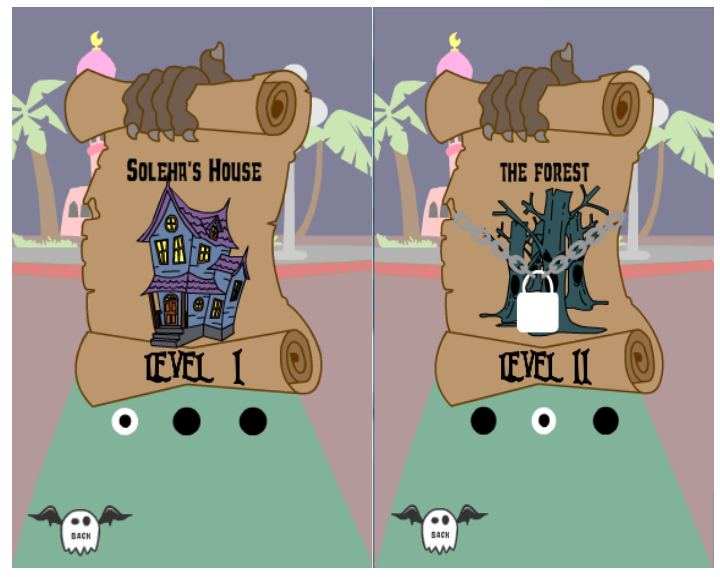

(i)

(ii)

Figure 2. (i) and (ii)The Game Leve| Screen

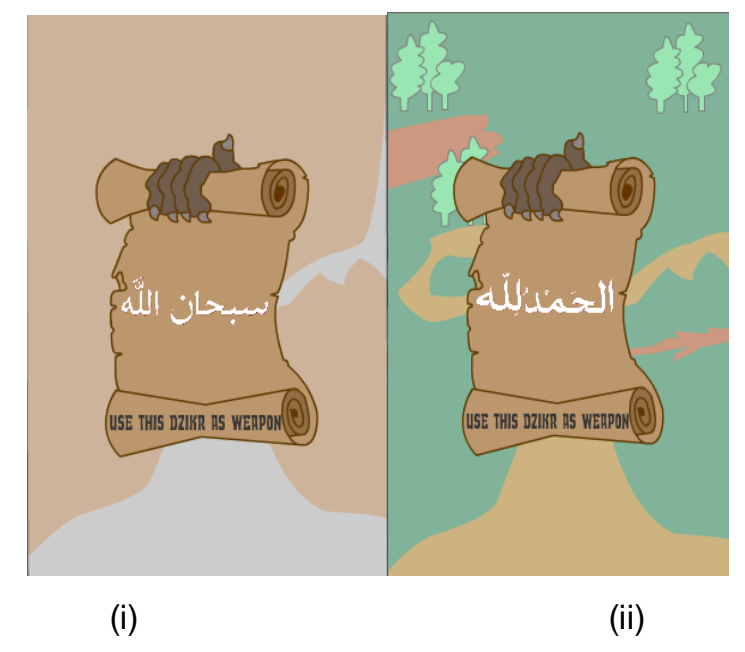

Figure 3.ZikIr(i) and (ii) as the Weapons for the Game

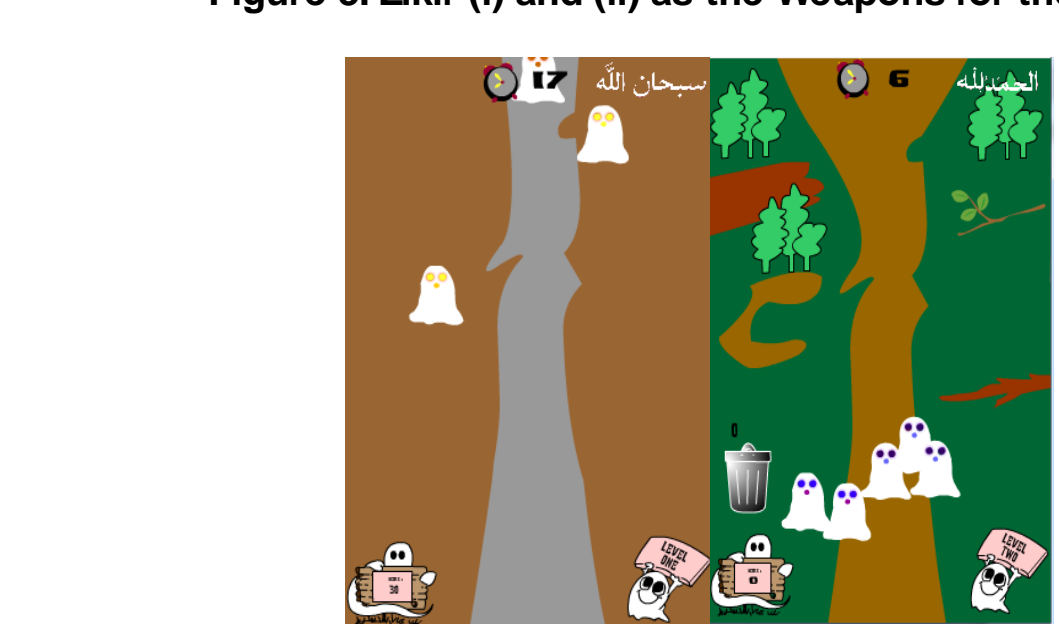

(i)

(ii)

Figure 4. (i) and (ii) the Game Modules 


\section{Results and Discussions}

The overall result of the review is summarized in Table 1 . Four main aspects have been focused in the technical evaluation. Among the aspects are contents, navigation/interactivity, application presentation and animation.

Table 1. Result on Expert Review

\begin{tabular}{|c|c|c|c|c|c|}
\hline Aspects & Criteria & Reviewer 1 & Reviewer 2 & Reviewer 3 & Average \\
\hline \multirow[t]{3}{*}{ Contents } & Delivery Approach & 5 & 4 & 4 & 4.33 \\
\hline & Easy to understand & 4 & 4 & 4 & 4 \\
\hline & $\begin{array}{l}\text { Provide examples that } \\
\text { clear and realistic }\end{array}$ & 4 & 4 & 3 & 3.67 \\
\hline \multirow[t]{2}{*}{$\begin{array}{l}\text { Navigation / } \\
\text { Interactivity }\end{array}$} & $\begin{array}{l}\text { Interactivity in } \\
\text { application }\end{array}$ & 5 & 4 & 4 & \\
\hline & $\begin{array}{l}\text { Understandable } \\
\text { navigation }\end{array}$ & 5 & 4 & 5 & 4.67 \\
\hline \multirow[t]{6}{*}{$\begin{array}{l}\text { Application } \\
\text { Presentation }\end{array}$} & $\begin{array}{l}\text { Attractive Screen } \\
\text { Design }\end{array}$ & 4 & & 4 & 4.33 \\
\hline & $\begin{array}{l}\text { Attractive colors, text, } \\
\text { graphic and images }\end{array}$ & 4 & & 5 & 4.67 \\
\hline & $\begin{array}{l}\text { Consistency and } \\
\text { functional icon }\end{array}$ & 5 & 5 & 4 & 4.67 \\
\hline & Instructions and guide & 5 & 5 & 5 & 5 \\
\hline & Suitable audio usage & & (4) & 4 & 3.67 \\
\hline & Suitable sound effects & 3 & 4 & 4 & 3.67 \\
\hline \multirow[t]{4}{*}{ Animation } & $\begin{array}{l}\text { Attractive color and } \\
\text { texture }\end{array}$ & 4 & 5 & 3 & 4 \\
\hline & $\begin{array}{l}\text { Movement smoothness } \\
\text { and transition }\end{array}$ & & 5 & 4 & 4.33 \\
\hline & Special Efiects & & 5 & 4 & 4.33 \\
\hline & & & & otal Average & $\begin{array}{l}59.67 / 14 \\
=4.26\end{array}$ \\
\hline
\end{tabular}

Overall average score from expert review towards the games resulted 4.26. According to [23] the criteria for the subject to be measured must show the average value of at least 4 on a Likert scale of (1) to 5 to indicate that it meets the standard. The next sub section will discuss each of aspects that had been reviewed by the technical experts.

\subsection{Aspect 1: Contents}

In contents aspect, stress is put on how delivery approach used in contents delivery. This examine whether the approach used is suitable for the level of user. While from the feaure of easy to understand, the contents provided in the game is understandable which part of usability is. Also, contents were evaluated whether it provides a clear and realistic example. Summary of the findings is depicted in Figure 5. 


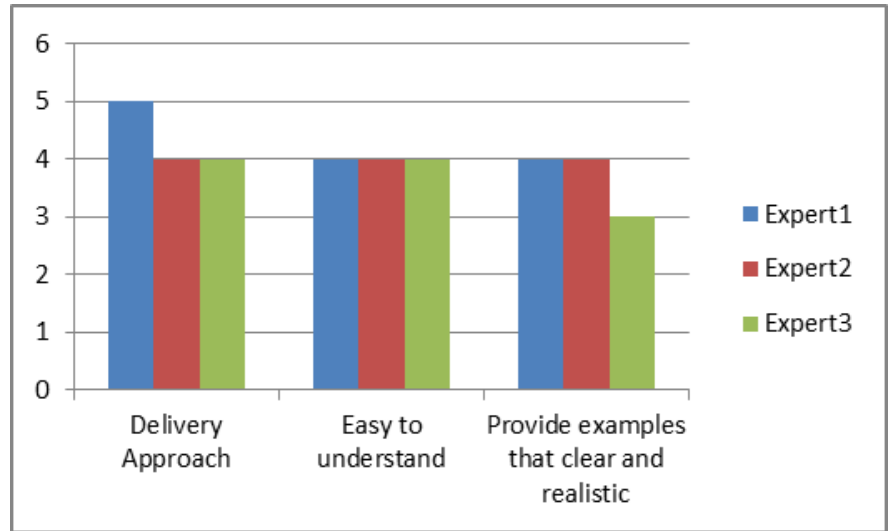

Figure 5. Result on Contents Aspect

From the above figure, the average result for contents in term of delivery approach is 4.33 while for easy to understand, all experts agreed that it achieve the scale of 4.0. Meanwhile, the last criteria in contents, which is provide examples that clear and realistic, the average score is 3.67 .

The first and second criteria in the contents aspects is fulfilled through the score that is 4.0 and above while for third criteria, since the score is below than 4.0, there is need for improvement before it can be disclose to the target user?

\subsection{As pect 2: Interactivity and Nayigation}

Second aspect examined by the experts is interactivity and navigation. Interactivity is known as the activity carried out simultapieously by two parties to achieve the same purpose [28] while Dewan Dictionary [29] define interactivity as an action or active communication between each other, it responses between two or more parties. On other hand, navigation is used to provide interactivity in multimedia application. The lowest level of interactivity is navigation Two criteria that going to be checked for interactivity and navigation aspect; whether the interactivity exists in the application and the navigation provided easy tozunderstand by the target user. Summary of the findings of this aspect is shown in Figure 6.

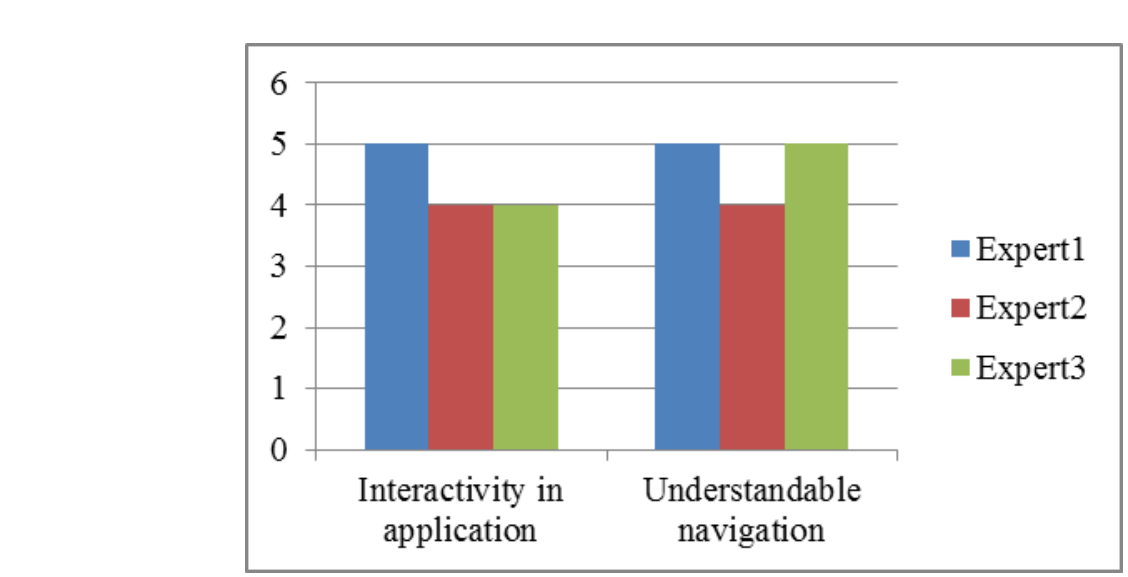

Figure 6. Result on Interactivity and Navigation

Both of criteria scores 4.33 and 4.67 respectively in average. This result indicates that both interactivity and navigation in this game provides an acceptable level of interactivity and navigation. 


\subsection{As pect 3: Presentation of the Prototype}

In this aspect, a few criteria have been embedded to be evaluated. This aspects concern on how the application is presented to the user in terms of:

a) Attractive Screen Design

In this criterion, the evaluation will look if the screen for user is attractive and followed the design principles in human computer interaction.

b) Attractive Colors, Text, Graphics and Images

This criteria focus on elements that integrated on the screen whether it is attractive or not. Elements that need to be considered are background colors, the text, graphics and images on the screen is well blended in terms of color and arrangements.

c) Consistency and Functional Icon

Consistency and functional icon is referring to the consistency use of icon in each modules or part throughout the application while functional icon stress on the functionality of each icon that displayed on the screen.

d) Instructions and Guide

This elements focus on instructions and guide provide to the user of the application. Instructions can be provided either through display of text or use of highlights, also can be through audio. The same approach can be used for user guides.

e) Suitable Audio Usage

In this part, the suitability for each audio that integrated in the application is examined. It need to be use in appropriate way to avoid confusion among target user. The language use and the volume level for audio file are evaluated.

f) Attractive Colors, Text, Graphics and Images

Sound effects act as supporting elements in orderto give rich experiences to the user. Sound effects gives an impact in multimedia presentation and for this evaluation, it will cater on the presence of sound effects and it 5 suitability.

After the review has been done by the experts, Figure 7 portrayed the summary of findings for application presentation aspeet.

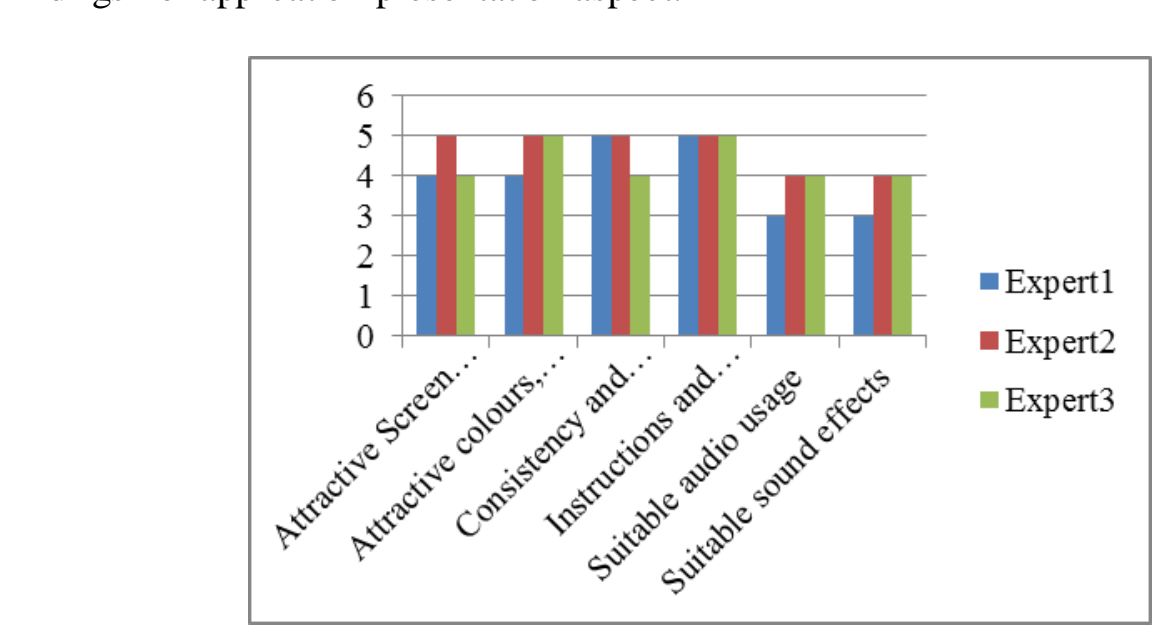

Figure 7. Result for Application Presentation Aspect

Attractive screen design, attractive colors, text, graphics and images, together with consistency and functional icon scores an average of 4.33, 4.67 and 4.33 respectively. Again, these criteria fulfill the requirement according to Nielson (1993). For instructions and guide, the average scores of 5.00 shows that this criteria almost complete at all. Despite of that, suitable audio usage and sound effects only scores 3.67, that is below than the level needed hence further works need to be carried on these criteria. 


\subsection{Aspect 4: Animation}

Animation plays an important role in multimedia application. It has been widely used to provide visualization to the user so the understanding level will be more higher compared to traditional method of information delivery. Among criteria in this aspect are the attractive colors and texture used, the smoothness of movement and special effects are taken into account. These three elements is needed to provide a good animation in multimedia application. Summary of results for these elements can be seen in Figure 8.

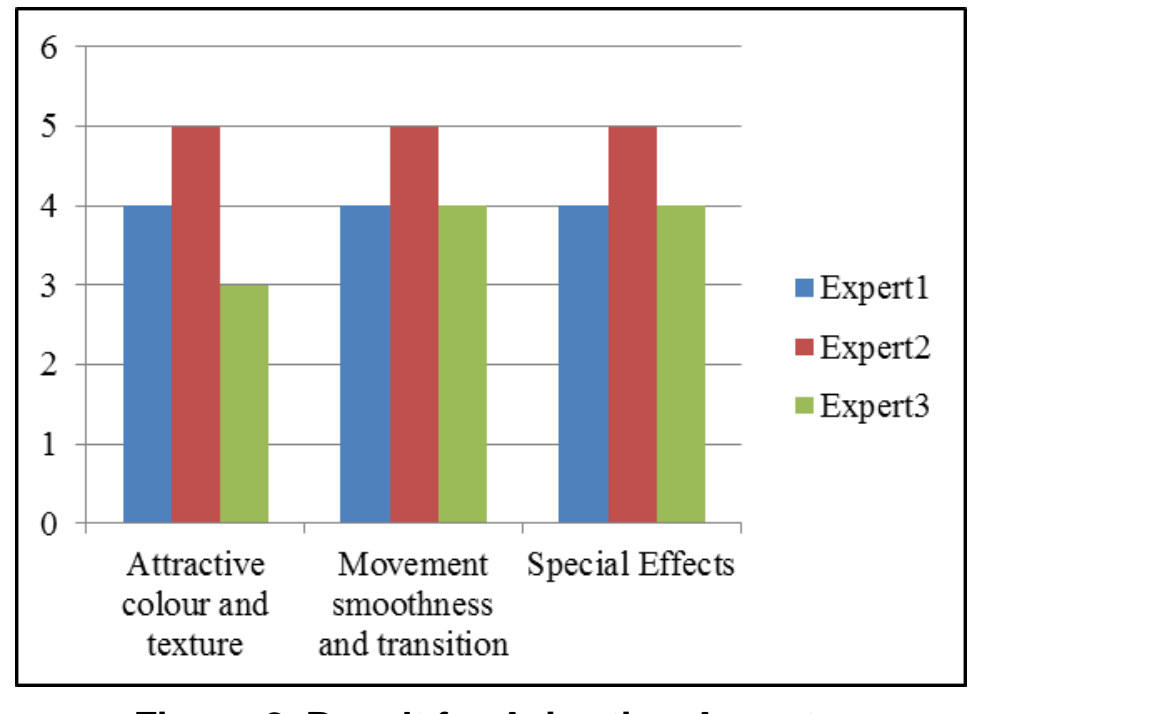

Figure 8. Result for Animation Aspect

For attractive color and texture, an average score of 4 is achieved according to the result obtain. While for movement shoothness and transition, the average result is 4.33. The same average score also collected for special effects, which is 4.33 . Since all the elements scores 4.00 and above it proved that it meets the level of animations standard for multimedia application.

\section{Conclusions}

As we know, the teehnology evolves rapidly. Multimedia technology has been widely used in many ways within various fields. Game is one of the areas that manipulate this technology. Ilots of game can be get easily through the internet. Anyway, most of currently available game use violence tools and it can give a bad impact to the user. It has been a motivation to develop a game that incorporated religious elements. In order to identify the strength and weakness of the developed games, an expert review on technical aspects of the game has been conducted. The result from expert review on technical aspects will be used as a guide to improve the games. Results obtained shown that most of the criteria in four aspects of evaluation scored an average of 4.00 and above except for three criteria with 3.67 of average score. The criteria are: provide examples that clear and realistic, suitable audio and suitable effects need to be carefully revised in order to fulfill the technical standards before it can be tested against target users.

\section{Acknowledgement}

This project has been registered with the Center of Research and Innovation Management (CRIM) of University Sultan Zainal Abidin (UniSZA) under a code number UNISZA/2014/PPL (036). MJTM was competed in UniSZA Innovation Competition 2015 and won Bronze medal. It also has been presented in $2^{\text {nd }}$ International Conference on 
Islamic Applications in Computer Science And Technology (IMAN2014) held in Amman, Jordan on October 2014. We would like to thanks the CRIM and UniSZA for believing in this project.

\section{References}

[1] Anderson C. A. and Warburton W. A., "The impact of violent video games: An overview", Growing up fast and furious: Reviewing the impact of violent and sexualised media on children, (2012), pp. 56-84.

[2] Rideout V. J., Foehr U. G. and Roberts D. F., "Generation M2: Media in the lives of 8-18 years old.Merlo Park", CA. Henry J. Kaiser Foundation, (2010).

[3] Lenhart A., Kahne J., Middaugh E., Macgill E. R., Evans C. and Vitak J., "Teens, video games and civics", Washington DC: PEW Internet and American Life Project, (2008).

[4] Dill K. E., Gentile D. A., Richter W. A. and Dill J. C., "Violence, Sex, Race, and Age in Popular Video Games: A Content Analy sis", (2005).

[5] N. A. Rawi, M. M. Amin, A. Rozaimee and W. M. W. Isa, "Teaching ZikirThrough 2D Games", $2^{\text {nd }}$ International Conference on Islamic Applications in Computer Science And Technology, 2014, Amman, Jordan, October 12-13, (2014).

[6] Alessi S. M. and Trollip S. R., “Computer-based instruction: Methods and development", New Jersey, NJ:Prentice-Hall, (1984).

[7] Kirikkaya E. B., İŞERİ Ş. and Vurkaya G., "A board game abouts space and solar system for primary school students", The Turkish Online Journal of Educational Tecrnology, vol 9, to. 2, (2010), pp. 1-13.

[8] Huizenga J., Akkerman S., Admiraal W. and Dam G. T., Mobile game-based learning in secondary education: engagement, motivation and learning in a mobile city game", Journal of Computer Assisted Learning, vol. 25 , no. 4, (2009), pp. 332-344.

[9] Papastergiou M., "Digital game-based learningin high schoel computer science education: impact on educational effectiven ess and student motivation") Computers \& Education, vol. 52, no. 1, (2009), pp. 112.

[10] Dickey M. D., "Murder on Grimm Isle The impact of game narrative design in an educational game based learning environment", $>$ British Journal of Educational Technology.doi:10.1111/j.14678535.2009.01032.x, (2010).

[11] Huang W. H., "Evaluating learners' motivational and cognitive processing in an online game-based learning environment", Computers in Human Behavior.doi: 10.1016/j.chb.2010.07.021, (2010).

[12] Tüzün H., Yılmaz S. M Karakuș T., Ina1 Y and Kızılkaya G., "The effects of computer games on primary school stuđents achievement and motivation in geo graphy learning", Computers \& Education, vol. 52, no. 1, (2009), pp. 68-77.

[13] Carbonaro M., \$zafron D., Cutumisu M. and Schaeffer J., "Computer-game construction: A gender neutral attractor to Computing Science", Computers \& Education, vol. 55, no. 3, (2010), pp. 1098-1111.

[14] Virvou M. Katsionis. G. and M anos K., "Combining Software Games with Education: Evaluation of its Educational Effectiveness", Educational Technology \& Society, vol. 8, no. 2, (2005), pp. 54-65.

[15] Yien J. M., Hung C. M. Hywang G. J. and Lin Y. C., "A Game-B ased Learning Approach To Improving Students' Learning Aclievements In A Nutrition Course", TOJET: The Turkish Online Journal of Educational Technology, vol. 10, no. 2, (2011), pp. 1-10.

[16] Ahmad W. F. W. Akhir E. A. P. and Azmee S., "Games-based Learning Courseware for Children with Learning Dísabilities”, 2010 International Symposium in Information Technology (ITSim), (2010), pp. 1-4.

[17] Bourgenjon J., Valcke M., Soetaert R. and Schellens T., "Students' perceptions about the use of video ganes in the classroom", Computers \& Education, vol. 54, no. 4, (2010), pp. 1145-1156.

[18] Warren S. J., Dondlinger M. J. and Barab S. A., "A MUVE towards PBL writing: effects of a digital learning environment designed to improve elementary student writing", Journal of Research on Technology in Education, vol. 41, no. 1, (2008), pp. 113-140.

[19] Terrell S. and Rendulic P., "Using computer- managed instructional software to increase motivation and achievement in elementary school children", Journal of Research on Computing in Education, vol. 26, no. 3, (1996), pp. 403-414.

[20] Yun R. W., Jiang Y. Y. and Li X., "The summaries of studies of application effectiveness of computer games in primary and secondary education", Distance Education Journal, vol. 28, no. 2, (2010), pp. 8692.

[21] Papastergiou M., "Exploring the potential of computer and video games for health and physical education: A literature review", Computers \& Education, vol. 53, no. 3, (2009), pp. 603-622.

[22] Patton M. Q., "The evaluator's responsibility for utilization. Evaluation Practice, vol. 9, no. 2, (1988), pp. 5-24.

[23] Nielsen J., "Usability Engineering”, Academic Press, Boston, MA, (1993).

[24] Crozat S., Hû O. and Trigano P., "A method for evaluating multimedia learning software", In Multimedia Computing and Systems, 1999. IEEE International Conference on, vol. 1, July (1999), pp. 714-719. 
[25] Lee S. H., "Usability testing for developing effective interactive multimedia software: concepts, dimensions, and procedures", Educational Technology \& Society, vol. 2, no. 2, (1999), pp. 1-13.

[26] Carreras C. and Rius J., "Evaluation of ICT Applications in the New Lleida Museum, Spain", Visitor Studies, vol. 14, no. 2, (2011), pp. 219-232.

[27] Kennedy G., Petrovic T. and Keppell M., "The development of multimedia evaluation criteria and a program of evaluation for computer aided learning", InASCILITE, vol. 98, (1998), pp. 407.

[28] Sims R., "Interactivity: A forgotten art?", Computers in Human Behavior, vol. 13, no. 2, (1997), pp. 157-180.

[29] Kamusdewan, "Dewan Bahasa danPustaka”, (2005).

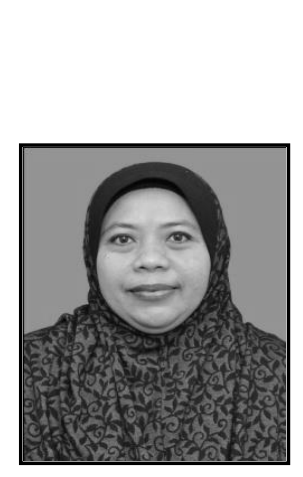

Authors

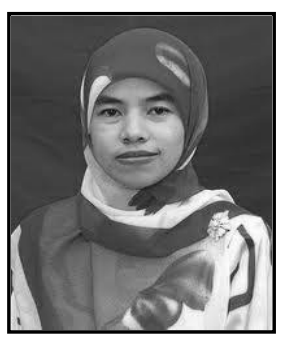

Norkhairani Abdul Rawi, She is a lecturer in Universit Sultan Zainal Abidin, Terengganu since 1998. In 1996, she holds a Diploma in Information Technology from Sultan Zainal Abidin Religious College (KUSZA). In 1998, she holds a Degree in Bachelor of Information Technology in Information Science (Hons) from University Kebangsaan Malaysia (OKM). She then pursues her study in MIT (Information Science) from University Kebangsaan Malaysia (UKM), Malaysia. Her research interests are Visual Informatics (VI) and Multimedia.

Maizan Mat Amin, She was born in Terengganu, Malaysia on $20^{\text {th }}$ March 1976, She obtained her Master of Science (Computer Science) majoring Multimedia in 2003 from Universiti Putra Malaysia, Bachelor of Intormation Technology (Information Science) in 999 from Universiti Kebangsaan Malaysia (UKM), and Diploma of Information Technology from Kolej Agama Sultan Zainal Abidin (currently known as Universiti Sultan Zainal Abidin (UnisZA)). She joined Universiti Sultan ZainalAbidin (UniSZA), Terengganu Malaysia since 1999 and one of the Lecturer at Faculty of Informatics and Computing, UniSZA. Her research interests are in Visualanformatics, Multimedia and Human Computer Interaction.

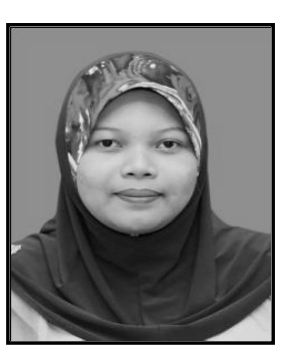

Azilawati Rozaimee, She is a lecturer in University Sultan Zainal Abidin, Terengganu. She holds a degree in Bachelor of Computer Science (Software Engineering) from Universiti Putra Malaysia (UPM) in 2006 and M. Sc. Com. (Software Engineering) from Universiti Putra Malaysia (UPM), Malaysia in 2008. Her research interests are Multimedia Technology and HumanMalaysia (UPM), Malaysia in 2008. Her research interests are Multimedia Technology and Human Computer Interaction (HCI).

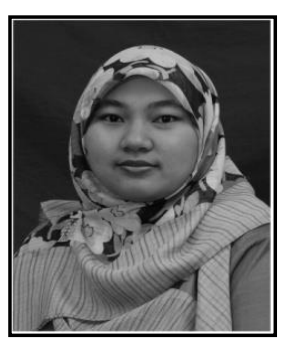

Wan Malini Wan Isa, She is a lecturer in Universiti Sultan Zainal Abidin, Terengganu. She holds a degree in Bachelor of Computer Science (Multimedia) from Universiti Putra Malaysia (UPM) in 2006 and M. Sc. Com. (Multimedia) from University Putra Malaysia (UPM), in 2008. Her research interests are Multimedia Technology and Human Computer Interaction (HCI). 


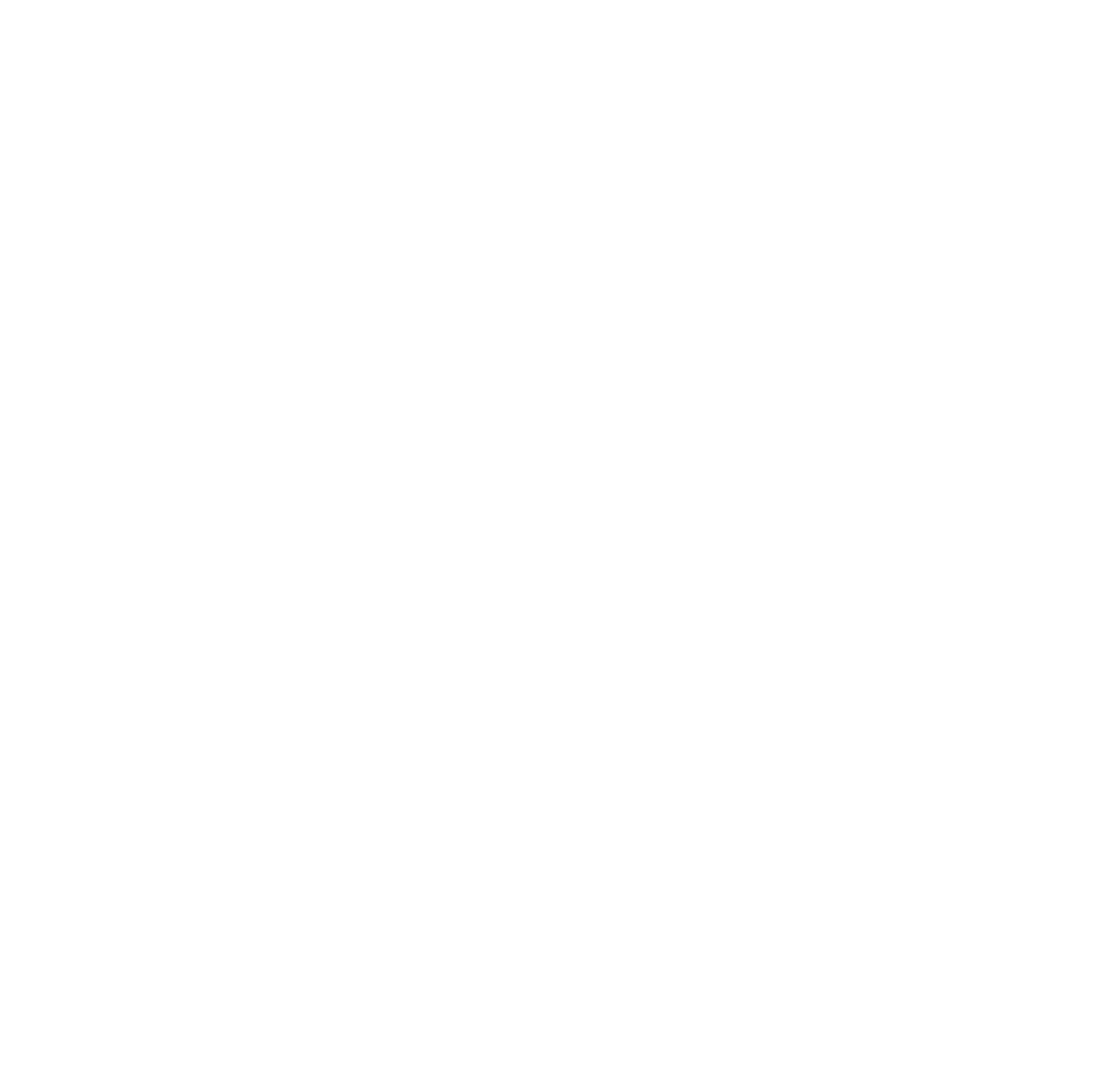

